\title{
Negative social emotions and cognition: Shame, guilt and working memory impairments
}

\author{
Cavalera Cesare $^{\mathrm{a}, \mathrm{b}, *}$, Pepe Alessandro ${ }^{\mathrm{c}}$, Zurloni Valentino ${ }^{\mathrm{c}}$, Diana Barbara ${ }^{\mathrm{c}}$, Realdon Olivia ${ }^{\mathrm{c}}$, \\ Todisco Patrizia $^{\mathrm{d}}$, Castelnuovo Gianluca ${ }^{\mathrm{a}, \mathrm{e}}$, Molinari Enrico ${ }^{\mathrm{a}, \mathrm{e}}$, Pagnini Francesco ${ }^{\mathrm{a}}$ \\ ${ }^{\text {a }}$ Catholic University of Milan, Via Nirone 15, Milan, Italy \\ ${ }^{\mathrm{b}}$ Unit of Epidemiological and Evaluation Psychiatry, IRCCS St John of God Clinical Research Centre, Via Pilastroni 4, Brescia, Italy \\ ${ }^{\mathrm{c}}$ University of Milan-Bicocca, Via Thomas Mann, 8, 20162 Milan, Italy \\ d Center of Eating Disorders, Casa di Cura Villa Margherita, Via Costacolonna, 6, 36057 Arcugnano, Italy \\ e Istituto Auxologico Italiano IRCCS, Psychology Research Laboratory, Verbania, Italy
}

A R T I C L E I N F O

\section{Keywords:}

Shame

Guilt

Working memory

Eating disorders

\begin{abstract}
A B S T R A C T
Negative emotions can have an impact on a variety of cognitive domains, including Working Memory (WM). The present work investigated whether shame and guilt modulate WM performance in a dual-task test both in a nonclinical and a clinical population. In Experiment 1, 76 non-clinical participants performed a dual-task before and after being randomly assigned to shame, guilt or neutral inductions elicited by the writing of autobiographical past experiences. Shame and guilt elicitations were related to impaired WM performances. In Experiment 2, 65 clinical inpatients with eating disorders were assigned to the same procedure. The negative relationship of selfconscious emotions and WM was confirmed. Taken together these results suggest that shame and guilt are related to impairments of WM in both clinical and non-clinical participants.
\end{abstract}

\section{Introduction}

Emotional processing exerts a strong influence over different types of cognitive performance (Gong, Xiao, \& Wang, 2016; Pessoa, 2008; Yiend, 2010). Working memory (WM) in particular seems to be strongly affected by emotional processing (Course-Choi, Saville, \& Derakshan, 2017; Iordan, Dolcos, \& Dolcos, 2013). WM is a dynamic encoding process, whereby information is acquired and updated repeatedly with new information (Miyake \& Shah, 1999). Research on cognitive processes evidenced that resources are utilized flexibly during attentional operations according to processing priorities (Yiend, 2010). Affective factors can modulate how information is stored and operated in WM (Baddeley, 2012), which is limited in terms of the amount of information that can be processed (Conway, Cowan, \& Bunting, 2001; Stout \& Rokke, 2010). Research on cognitive and affective tasks has evidenced that pervasive negative state emotions presented as distracting stimuli have associations with deterioration of WM performance (Magee \& Zinbarg, 2007; Mitchell \& Phillips, 2007; Storbeck, Davidson, Dahl, Blass, \& Yung, 2015). Following preliminary findings, there are several aspects of the relationship between negative emotions and WM that still need to be explored related for example to negative social emotions implications on cognitive processes. Shame and guilt are distinctive negative self-conscious emotions that arise from selfrelevant transgression and failures (Tracy, Robins, \& Tangney, 2007). Despite many similarities, the two emotions differ in their trajectories. Whereas guilt involves self-criticism towards a specific personal action and is associated with the harm that it may have caused to others, shame is related to a negative evaluation of the self, with the subsequent desire to hide or escape from a bad situation (Lewis, 1971; Tangney, Stuewig, \& Mashek, 2007).

Although the relationship between negative 'basic' emotion (anger, sadness, disgust, fear) and WM has been widely examined in both clinical and non-clinical populations (Allen, Schaefer, \& Falcon, 2014; Magee \& Zinbarg, 2007; Schweizer \& Dalgleish, 2016), there is limited evidence about the influence of 'negative' self-conscious emotions, such as shame and guilt, on WM and cognitive control processes. Accessible and vivid memories related to self-conscious emotions provide the structure for personal autobiographical narratives and the reference points from which we make attributions and inferences in everyday life (Tracy et al., 2007). As shame and guilt convey crucial information about the way we consider ourselves, their elicitation can have a big impact on WM process especially if WM is concurrently acquiring other

\footnotetext{
* Corresponding author at: Department of Psychology, Via Nirone 15, 20123 Milan, Italy.

E-mail addresses: cesarem.cavalera@unicatt.it (C. Cavalera), alessandro.pepe1@unimib.it (A. Pepe), valentino.zurloni@unimib.it (V. Zurloni), barbara.diana@unimib.it (B. Diana), olivia.realdon@unimib.it (O. Realdon), ptodis@tin.it (P. Todisco), gianluca.castelnuovo@unicatt.it (G. Castelnuovo), enrico.molinari@unicatt.it (E. Molinari), francesco.pagnini@unicatt.it (F. Pagnini).
} 
information. Dopamine plays a crucial role in enhancing WM processes (Söderqvist et al., 2012) and as recursive shame and guilt experiences are related to depressive symptoms and to a diminished dopaminergic response (Kim, Thibodeau, \& Jorgensen, 2011), these emotions could be both related to negative WM performances. Moreover, evidences showed that shame is strongly implicated in cortisol increases (Gruenewald, Kemeny, Aziz, \& Fahey, 2004a, 2004b) that are related to WM impairments and memory retrieval (Oei, Everaerd, Elzinga, Well, \& Bermond, 2006). Therefore shame may have greater impact than guilt in terms of predicting worse WM performances.

As a lot of studies that involved people with psychiatric diagnoses (Adler, Holland, Schmithorst, Tuchfarber, \& Strakowski, 2004; Christopher \& MacDonald, 2005; Williams et al., 2007) showed a detrimental effect of negative emotions on cognitive performances, it may particularly useful assess the link between negative self-conscious emotions and cognitive performances both in healthy populations and in those clinical populations with a susceptibility to negative self-conscious emotions. Within this perspective shame and guilt are considered to have a key role in people with eating disorders (Cavalera et al., 2017; Ferreira, Matos, Duarte, \& Pinto-Gouveia, 2014; Gilbert \& Miles, 2014; Levinson, Byrne, \& Rodebaugh, 2016; Manzoni et al., 2009). Whereas anorexics often try to cope with guilt and shame prompted by the 'indulgent' act of eating, bulimic episodes of overeating are also marked by a profound sense of loss of control that elicits guilt and self-criticism (Garner \& Garfinkel, 1985). Moreover, evidences underlined a link between WM capacity and cognitive strategies that are crucial for symptoms reduction in eating disorders (Brooks, 2016; Israel et al., 2015). More recently, Brooks, Funk, Young, and Schiöth (2017) evidenced that in some subtypes of eating disorder such as anorexia, working memory capacity may underlie excessive cognitive control and attention to details that can be related to the management cognitive control of appetite. Therefore, more evidences are needed in order to assess a possible link between negative self-conscious emotions and WM performances. Such a study may highlight a strong detrimental effect of negative self-conscious emotions on WM and it could better direct psychotherapy for eating disorders throughout the clinical practice in order to reduce the effect of such negative emotions before learning cognitive strategies.

The present study aims to explore the nature of the relationship between negative self-conscious emotions and WM performances, evaluated through a dual-task condition in two experiments involving a non-clinical group (Experiment 1) and a group composed by inpatients presenting different subtypes (anorexic, bulimic, binge eating, OSFED) of eating disorders (Experiment 2). We hypothesized that: (1) guilt and shame both have negative effects on dual-task performances; (2) shame has greater impact than guilt in terms of predicting worse WM performances. We tested the hypotheses in a sample from the general population and in a clinical sample composed of people with eating disorders.

\section{Experiment 1}

\subsection{Method}

\subsubsection{Participants}

Seventy-six young female adults (22.46 years old \pm 3.76 ) attending different faculties of the University of Milan-Bicocca volunteered to participate in this research. The choice of different faculties was aimed at "randomizing" different cohorts of undergraduates with heterogeneous professional interests. During the first meeting with participants, basic preliminary information about the study protocol were provided. All participants were informed that the study was aimed at understanding the relation between memory and negative emotions. All participants provided written informed consent as required by the ethics committee of University of Milan-Bicocca and they were randomly assigned to one of the three writing condition; all participants were free to stop the experimental procedure whenever they wanted to. During the final debriefing session, special attention was paid to participants' psychological health and wellbeing after the experimental procedure.

\subsubsection{Procedure}

The procedure was composed of three steps (Fig. 1). In the first one, participants were individually received at a university lab and administered a dual-task test (Della Sala, Foley, Beschin, Allerhand, \& Logie, 2010). First, the digit span of each person was assessed before the digit recall task, in an attempt to control individual differences in individual WM capacity (Della Sala et al., 2010). The dual-task procedure consisted of performing digit recall and a tracking task, first separately and then simultaneously, in accordance with Della Sala et al.'s (2010) procedures. The performance measures were the proportion of digits recalled accurately and the number of circles crossed by the pencil. Proportional performance in digit recall was calculated by measuring the change in digit recall between single- and dual-task conditions.

Proportional performance in tracking was calculated by measuring the change in tracking between single- and dual-task conditions. Proportional performance in both tasks combined $([1)$ was calculated by adding proportional performance in tracking and in digit recall task (Della Sala et al., 2010).

In the second step, participants were randomly assigned to one of the three different writing disclosure instructions of $15 \mathrm{~min}$ to elicit different negative social emotion experiences (Tangney \& Dearing, 2002):

- Shame writing condition (SWC): 'In the next 10 min I would like you to write about an unpleasant experience in which you felt really ashamed. It should be a situation where you felt so bad about yourself that you wanted to deny it or to hide and run away. Try to let go and express all your thoughts and innermost feelings. Write freely without worrying about mistakes. This paper will not be read by anyone and you can do whatever you want with it'.

- Guilt writing condition (GWC): 'In the next $10 \mathrm{~min}$ I would like you to write about an unpleasant experience in which you felt really guilty. It should be a situation where you felt so inadequate that you wanted to confess or amend the situation. Try to let go and express all your thoughts and innermost feelings. Write freely without worrying about mistakes. This paper will not be read by anyone and you can do whatever you want with it'.

- Neutral writing condition (NWC): 'In the next $10 \mathrm{~min}$, I would like you to write about the furniture of the room you are in. Describe what you see avoiding emotional content or stressful thoughts.

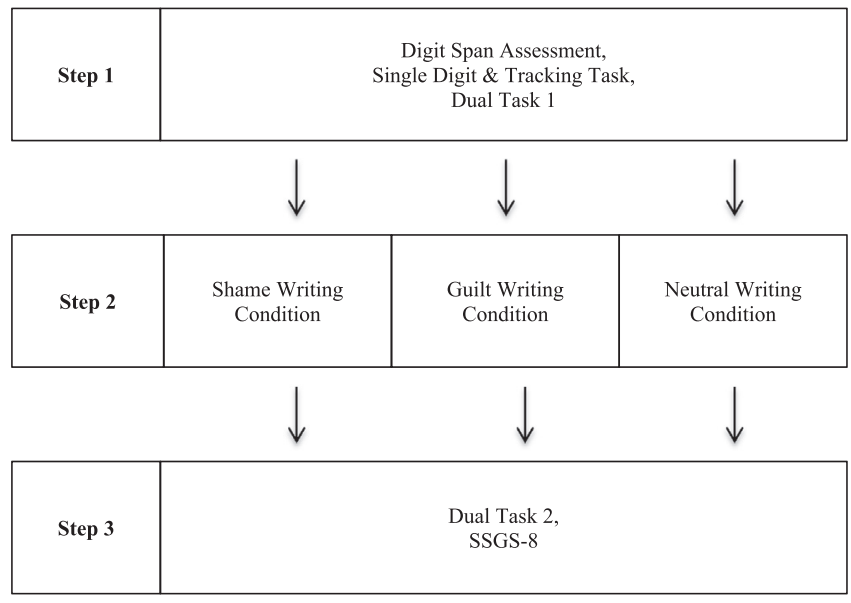

Fig. 1. Experiment 1 procedure. 
Write freely without worrying about mistakes. This paper will not be read by anyone and you can do whatever you want with it'.

Participants were randomly assigned to one of these three different writing conditions (GWC $=25$, SWC $=25, \mathrm{NWC}=26$ ). Before the writing disclosure task, the experimenter reassured all participants that no one would ever read the contents of the written text, that their personal privacy would not be violated and that any bias related to social desirability would be eliminated. Then the experimenter left the room to avoid interfering with the emotional experience disclosure.

In the third step, the experimenter re-entered the room and administered the digit recall and tracking task simultaneously again in order to evaluate potential differences in WM performances. As before, proportional performance in both tasks ( $(2)$ combined was calculated by adding proportional performance in tracking and in digit recall task (Della Sala et al., 2010). Immediately after this, participants were administered the Italian version of the Shame and Guilt State Scale (SGSS8) (Cavalera, Pepe, Diana, Zurloni, \& Realdon, 2017) in order to assess the current levels of shame and guilt elicited by the different writing tasks. SGSS-8 is a self-rating scale of current (state) feelings of shame and guilt. Eight items (four for each subscale) are rated on a five-point Likert scale.

Finally, a debriefing session at the end of the procedure was provided for all the participants in order to offer a help to cope with possible negative emotions elicited or to provide further information about the study protocol.

\subsubsection{Data analysis}

Based on Cohen (1992), and assuming a large effect size $(>0.60)$ (Cavalera \& Pepe, 2014), a power sample analysis was performed in order to detect an effect at the level of $p<0.05$ with $80 \%$ power. The analysis was conducted with the software G-power (version 3.1.9), a minimum of 21 participants would be necessary when entering three groups in a repeated-measures ANOVA (Cohen, 1992).

To analyze the results, we used a repeated measures analysis of variance (ANOVA), with main effects for time and group, and a Time $\mathrm{X}$ Condition (GWC, SWC, NWC) interaction term. Specifically, we focused on Time X Group interactions, which suggest differential change over time by group, considering the dual-tasks scores obtained before $([1)$, and after $(\{2)$ the emotional writing procedure as dependent variables. Subsequently, in order to determine the relative contributions of shame and guilt to increases in deterioration of dual-task performances, a oneblock hierarchical regression with enter method was applied (see Pedhazur, 1997 for further information). The regression model was set with the $\Delta$ dual task ( $(2-(1)$ as target variable and state shame and guilt scores from SGSS-8 as independent determinants.

In order to determine the relative contributions of shame and guilt on working memory performances for participants assigned to GWC and SWC, both state guilt and state shame were added in step 1. For participants assigned to NWC, a last regression was run with both state shame and state guilt included in step 1. Regression assumptions (e.g., homoscedasticity, multivariate normality) were checked and found to be fulfilled for all variables. Finally, a $p<0.001$ Mahalanobis'distance criterion was used to identify and skip multivariate outliers. Two different measures were created on the based of both 4 items of guilt and shame. As a result, four cases were excluded from the sample, three from GWC and one from SWC. All regression models were evaluated through statistically significant variation of $R^{2}$ and Cohen's (1988) effect size f2. SGSS-8 reliability scores (Cronbach's Alpha) were equal to 0.81 and 0.84 for shame and guilt scores respectively.

\subsection{Results}

A 3 (Writing Condition) $\times 2$ (Time) mixed ANOVA analysis yielded main effects of Time $\mathrm{F}(1,69)=45.89, \quad p<0.001, \quad \eta^{2}=0.40$ $\left(\left(1>\int 2\right)\right.$. A Writing Condition X Time interaction $\mathrm{F}(2,69)=32.59$, $p<0.001, \eta^{2}=0.49$, further indicated that the effect of the manipulation was stronger on emotional writing conditions versus neutral condition.

As shown in Table 1, 2 were significantly lower than 1 for GWC and SWC indicating a detrimental effect of negative self-conscious emotions on cognitive performances.

In order to determine the relative contributions of shame and guilt to increases in deterioration of dual-task performances, a one-block hierarchical regression with enter method was applied.

The first regression was performed in participants assigned to GWC using the $\Delta$ dual task as dependent variable and guilt as independent variable in step 1 (Table 2). Guilt was a statistically significant determinant of differences in the $\Delta$ dual task $\left(R^{2}=0.324, F(2\right.$, $21)=4.54, p<0.05)$. The regression for SWC was performed between $\Delta$ dual task as dependent variable and shame as independent variable in step 1 (Table 2). In line with what we expected, shame level was a statistically significant predictor of dual-task retest impairment $\left(R^{2}=0.345, F(2,23)=5.52, p<0.05\right)$.

The last regression in NWC was performed between $\Delta$ dual task as the dependent variable, and guilt and shame entered in step 1 (Table 2). As expected for the neutral writing group, guilt and shame did not make a significant contribution to the prediction of $\Delta$ dual task $\left(R^{2}=0.052, F\right.$ $(2,25)=0.63, p=n s)$.

As shown by Fig. 2, these results are consistent with the prediction that negative self-conscious emotions determine significant impairments in WM.

In line with Hypothesis 1, shame and guilt emotional experiences predicted negative effects on dual-task performances. More specifically, shame seemed to show a greater impact than guilt in predicting worse WM performances: comparing negative self-conscious emotions $\mathrm{R}^{2}$ in SWC and GWC showed that shame and guilt contribution to the prediction of $\Delta$ dual task accounted respectively for $34.5 \%$ and $32.4 \%$ of the explained variance.

\section{Experiment 2}

In order to assess negative self-conscious emotions' detrimental effect on WM in a clinical sample, Experiment 2 tested shame and guilt' effects on dual-task performances involving in-patients with eating disorders.

\section{Table 1}

$\int 1, \int 2$ and $\Delta$ Dual-task descriptive statistics of GWC, SWC and NWC in Experiment 1.

\begin{tabular}{|c|c|c|c|c|c|c|}
\hline & \multicolumn{2}{|l|}{ GWC } & \multicolumn{2}{|l|}{ SWC } & \multicolumn{2}{|l|}{ NWC } \\
\hline & $m$ & $s d$ & $m$ & $s d$ & $m$ & $s d$ \\
\hline $\int 1$ & 124.04 & 60.39 & 113.83 & 19.54 & 103.19 & 14.07 \\
\hline 2 & 106.10 & 57.41 & 89.61 & 16.58 & 110.36 & 19.44 \\
\hline$\Delta$ Dual-task & 17.94 & 11.95 & 24.22 & 12.62 & -6.18 & 18.26 \\
\hline
\end{tabular}

Table 2

Regression analysis of changes in dual task performance on shame and guilt scores (SGSS-8) in Experiment 1.

\begin{tabular}{lllll}
\hline Dependent Variable & Independent variable & B & $t$ & $P$ \\
\hline $\begin{array}{l}\text { Condition G } \\
\Delta \text { Dual-task }\end{array}$ & Guilt & & & \\
& Shame & 2.62 & 2.70 & 0.01 \\
& & -0.96 & -0.955 & 0.35 \\
Condition S & Guilt & & & \\
$\Delta$ Dual-task & Shame & -1.39 & -1.69 & 0.11 \\
& & 3.98 & 3.29 & 0.003 \\
Condition N & Guilt & & & \\
$\Delta$ Dual-task & Shame & 1.23 & 0.301 & $\mathrm{~ns}$ \\
& & -5.08 & -1.12 & $\mathrm{~ns}$ \\
\hline
\end{tabular}




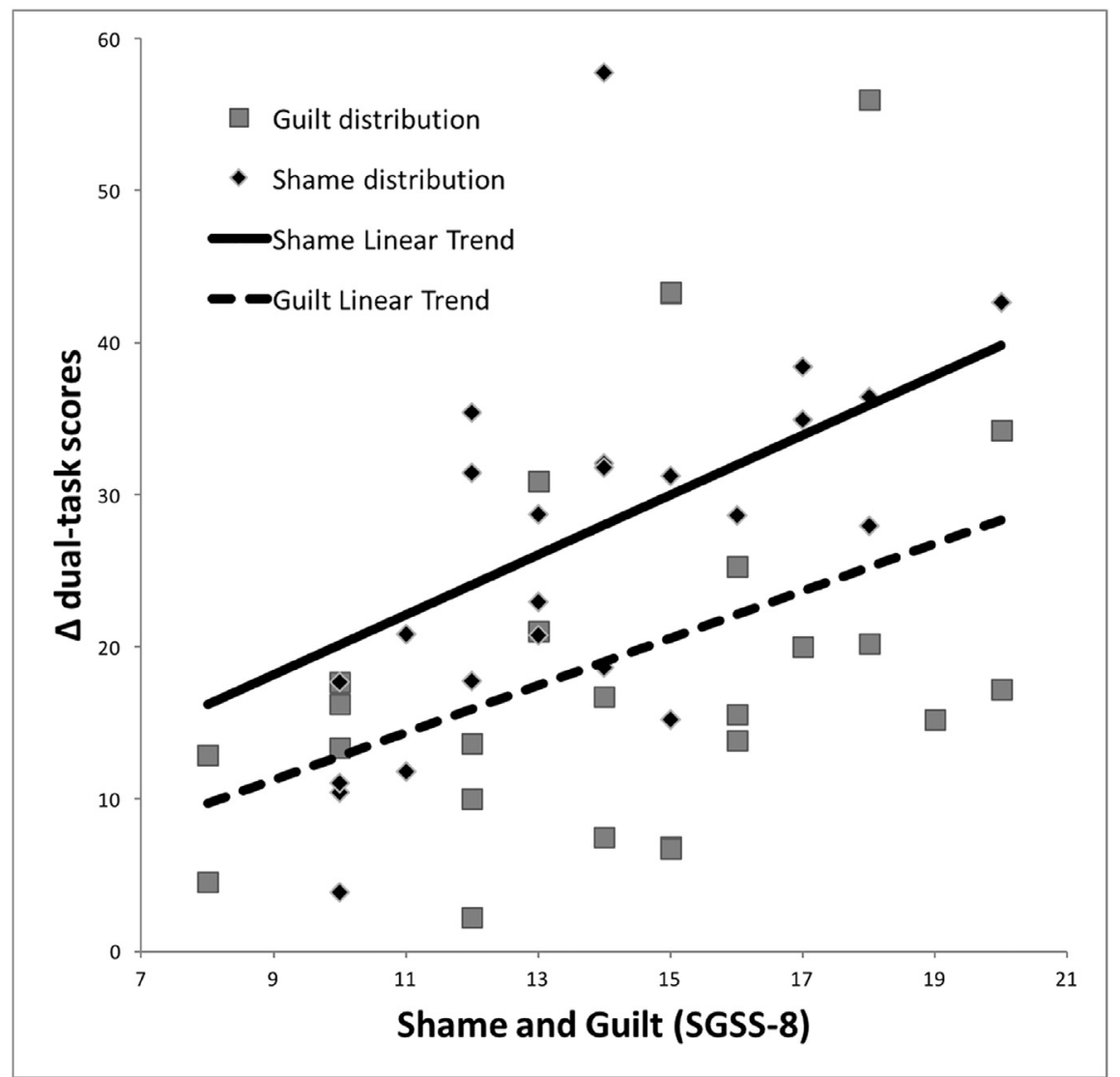

Fig. 2. Experiment 1 Shame trend and distribution in SWC and guilt trend and distribution in GWC.

\subsection{Method}

\subsubsection{Participants}

Sixty-five female adults (24.5 years old \pm 5.7 ) hospitalized for eating disorder behaviors participated in this experiment. The present sample was composed of $56.9 \%$ of patients with anorexic behaviors, $24.6 \%$ of patients with bulimic behaviors, $14 \%$ of patients with binge eating disorders and $4.5 \%$ of patients with OSFED behaviors. As in

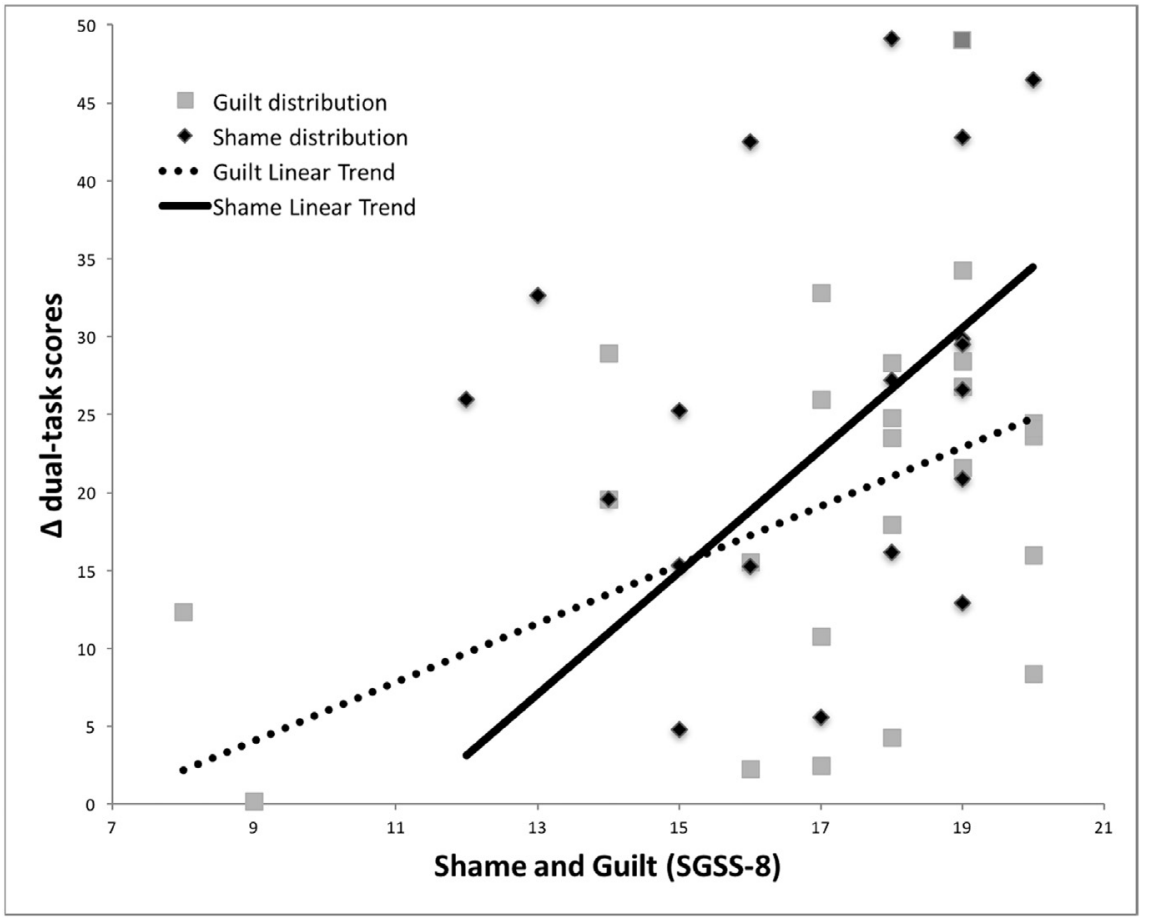

Fig. 3. Experiment 2 Shame trend and distribution in SWC and guilt trend and distribution in GWC. 
Table 3

$\lceil 1,\lceil 2$ and $\Delta$ Dual-task descriptive statistics of GWC, SWC and NWC in Experiment 2.

\begin{tabular}{|c|c|c|c|c|c|c|}
\hline & \multicolumn{2}{|l|}{ G } & \multicolumn{2}{|l|}{ S } & \multicolumn{2}{|l|}{$\mathrm{N}$} \\
\hline & $m$ & $s d$ & $m$ & $s d$ & $m$ & $s d$ \\
\hline $\int 1$ & 108.34 & 24.25 & 106.67 & 20.39 & 91.70 & 16.94 \\
\hline 2 & 90.13 & 21.57 & 83.75 & 20.97 & 108.49 & 22.01 \\
\hline$\Delta$ Dual-task & 18.21 & 10.20 & 22.92 & 17.97 & -16.79 & 13.16 \\
\hline
\end{tabular}

Table 4

Regression analysis of changes in dual task performance on shame and guilt scores (SGSS-8) in Experiment 2.

\begin{tabular}{lllll}
\hline Dependent Variable & Independent variable & $\mathrm{B}$ & $t$ & $P$ \\
\hline $\begin{array}{l}\text { Condition G } \\
\Delta \text { Dual-task }\end{array}$ & Guilt & & & \\
& Shame & 1.83 & 2.24 & 0.036 \\
& & -0.05 & -0.07 & $\mathrm{~ns}$ \\
Condition S & Guilt & & & \\
$\Delta$ Dual-task & Shame & -1.46 & -1.22 & $\mathrm{~ns}$ \\
& & 5.62 & 3.06 & 0.007 \\
Condition N & Guilt & & & \\
$\Delta$ Dual-task & Shame & 2.99 & 0.73 & $\mathrm{~ns}$ \\
& & 1.52 & 0.49 & $\mathrm{~ns}$ \\
\hline
\end{tabular}

Experiment 1, all participants volunteered to take part in the present study and no compensation was provided for them. All diagnosis were consistent with Diagnostic and Statistical Manual of Mental Disorders, Fifth Edition (DSM-5) (American Psychiatric Association, 2013). As in Experiment 1, a first session was set to provide preliminary information about the study protocol. All participants were informed that the experiment was focused to better understand the relation between memory and negative emotions and provided written informed consent and personal information treatment authorization. All participants were randomly assigned to one of the three different writing conditions (GWC $=27$, SWC $=22$, NWC $=16$ ) and were allowed to end the experimental procedure whenever they wanted to. During the final debriefing session, special attention was paid to participants' psychological health and wellbeing after the experimental procedure.

\subsubsection{Procedure}

The procedure was the same as in Experiment 1, mirroring the same three steps shown in Fig. 1. The only exception was the setting: patients were individually received in a quiet hospital room free of distractions or disturbing stimuli. Data analysis was the same as in Experiment 1. A $p<0.001$ Mahalanobi's distance criterion was used to identify and skip multivariate outliers. Two different measures were created on the based of both 4 items of guilt and shame. As a result, four cases, two from GWC and two from SWC, were excluded from the sample. SGSS-8 reliability scores (Cronbach's Alpha) were equal to 0.82 and 0.86 for shame and guilt scores respectively.

\subsection{Results}

A 3 (Writing Condition) $\times 2$ (Time) mixed ANOVA analysis yielded main effects of Time $\mathrm{F}(1,58)=20.06, p<0.001, \eta^{2}=0.257$ $\left(\left(1>\int 2\right)\right.$. A Writing Condition X Time interaction $\mathrm{F}(2,58)=42.57$, $p<0.001, \eta^{2}=0.595$, further indicated the effect of the manipulation was stronger on emotional writing conditions versus neutral condition (Table 3).

As shown in Table 3, 2 were significantly lower than 11 for GWC and SWC indicating a detrimental effect of negative self-conscious emotions on cognitive performances.

In order to determine the relative contributions of shame and guilt to increases in deterioration of dual-task performances, a one-block hierarchical regression with enter method was applied.

The first regression was performed between participants assigned to GWC using the $\Delta$ dual task as dependent variable and guilt as independent variable in step 1 (Table 4). Guilt was a statistically significant determinant of differences in the $\Delta$ dual task $\left(R^{2}=0.36, F(2\right.$, 24) $=6.19, p<0.01$ ).

The regression for the SWC was performed between $\Delta$ dual task as target variable and shame as independent predictor in step 1 (Table 4). In line with our expectation, shame level was a statistically significant predictor of dual-task retest impairment $\left(R^{2}=0.371, \mathrm{~F}(2,19)=5.02\right.$, $p<0.05$ ). The last regression in NWC was performed between $\Delta$ dual task as the dependent variable, guilt and shame being entered in step 1 (Table 4). As expected for the neutral writing group, guilt and shame did not make a significant contribution to the prediction of $\Delta$ dual task $\left(R^{2}=0.048, \mathrm{~F}(2,15)=0.329, p=\mathrm{ns}\right)$.

As shown by Fig. 3, these results are consistent with the prediction that negative self-conscious emotions determine significant impairments in WM and that dual task performances are more disrupted by shame than guilt.

In line with Hypothesis 1, shame and guilt emotional experiences predicted negative effects on dual-task performances. More specifically, shame seemed to show a greater impact than guilt in predicting worse WM performances: comparing negative self-conscious emotions $\mathrm{R}^{2}$ in the $\mathrm{S}$ and $\mathrm{G}$ conditions showed that shame and guilt's contribution to the prediction of $\Delta$ dual task accounted respectively for $37.1 \%$ and $36 \%$ of the explained variance.

\section{General discussion}

The relation between cognition and emotion has been increasingly explored in literature but no study has explored the relation between negative self-conscious emotions and cognitive performances. More specifically, apart from one previous exploratory study (Cavalera \& Pepe, 2014), no studies have analyzed the negative effects of these emotions on cognition in either clinical or non-clinical samples. Therefore, the present study aimed to explore the nature of the relationship between negative self-conscious emotions and WM performances evaluated through a dual-task condition in a non-clinical group and in an eating disorder group.

In both Experiment 1 and Experiment 2, the obtained results evidenced that shame and guilt writing conditions had negative effects on dual-task performances, evidencing a detrimental effect on WM both in the clinical and in the non-clinical sample (Hypothesis 1). These data confirmed that as shown by literature related to 'basic' negative emotions (Curci, Lanciano, Soleti, \& Rimé, 2013; Klein \& Boals, 2001) negative self-conscious emotions were also associated with poor performance in WM tasks. These data could be related to an intrusive effect elicited by shame and guilt that contrasts with the dual-task demands reducing WM capacity (Klein \& Boals, 2001).

As evidenced by previous studies interested in the relationship between negative emotions and memory (Curci et al., 2013; Wiswede, Münte, Goschke, \& Rüsseler, 2009), it is possible that the elicitation of shame and guilt by the writing of an autobiographical experience is related to impairments in executive capacity that limits an individual's ability to remain focused on an attention-demanding situation. As a result of negative emotions' elicitation, intrusive thoughts and worries can impede cognitive processing.

Therefore, data from Experiment 1 and Experiment 2 suggest that in both the clinical and non-clinical samples negative self-conscious emotions are related to a detrimental effect that impairs WM. More specifically, if we consider $R^{2}$ values from regression in the $G$ and $S$ conditions of both Experiments, shame showed greater impact than guilt in predicting worse WM performances in both the clinical and non-clinical sample (Hypothesis 2). This is consistent with literature about shame and guilt that evidenced that even though shame and guilt are both disruptive emotions shameful emotional experiences are 
characterized by feelings of worthlessness and powerlessness that are in turn associated with an unworthy self (Robinaugh \& McNally, 2010). As self-conscious emotions are inextricably linked to the self, they provide the structure for personal autobiographical narratives and the reference points from which we make attributions and inferences in everyday life (Orth, Robins, \& Soto, 2010). Shame and guilt convey key information about the self and this can help to explain why their elicitation have a big impact on WM process during a paper and pencil dual-task procedure. Moreover, since shameful experiences attack the whole sense of personal identity (Tangney \& Dearing, 2002), it is possible that their elicitation through past memories requires a greater supply of attentional resources than guilty past experiences.

More specifically, data seems to suggest a greater detrimental effect of negative self-conscious emotions in eating disordered patients than in non-clinical participants. In the clinical sample, shame and guilt's $\mathrm{R}^{2}$ contribution to the prediction of $\Delta$ dual task accounted respectively for $37.1 \%$ and $36 \%$ of the explained variance and in the non-clinical sample for $34.5 \%$ and $32.4 \%$ of the explained variance. These data seem to suggest that cognitive performances of eating-disordered patients might be particularly disrupted by shame and guilt domains. In particular $R^{2}$ values evidenced that shame elicitation is particularly disrupting for WM performances in eating-disordered patients. This is consistent with previous literature that showed how shameful experiences are a strong maintaining factor of eating disorder pathology (Doran \& Lewis, 2012; Keith, Gillanders, \& Simpson, 2009; Wong \& Qian, 2016). Patients with eating disorders have often experienced real or perceived experiences of humiliation and rejection crucial in the development of inner defectiveness which they try to manage by means of disordered eating behaviors (Matos, Ferreira, Duarte, \& PintoGouveia, 2015). Therefore, it is possible that the momentary elicitation of these negative experiences through the writing task was related to a strong impairment of the attentional resources required by the dualtask procedure.

We acknowledge that the generalization of the results is limited by the study limitations. Firstly, shame and guilt have been here compared to a neutral non-emotional condition: more research is needed in order to compare the degree of cognitive impairments observed by negative self-conscious emotions elicitations to the effect of other positive emotions such as joy and negative emotions such as anger or disgust. Moreover, the sample was composed only by female participants (and limited to undergraduate students for the non-clinical sample), and therefore it cannot be generalized to the general population. Future studies could include a larger and a more generalizable sample. Moreover, the sample size of clinical ED inpatients was sufficient for the analysis but was nonetheless relatively small. Finally, the elicited emotions may have had an alteration as the experimenter re-entered the room. This could have partially amplified or decreased these emotional experiences after the writing disclosure task.

Given these considerations, the present findings have however shed light on the relationship between negative self-conscious emotions and WM performances. Shame and guilt elicitations seemed to be related to impairments in the executive functions of WM in both clinical and in non-clinical participants. The present results could help teachers and counsellors to consider the role of negative self-conscious emotions throughout the learning process and to help to develop a better attitude during stressful situations where high WM performances are needed. Moreover, these initial data provide some relevant information for the clinical work with eating disorders because they suggest the importance of working on guilty and shameful memories in order to make available more WM resources that are crucial in the learning of cognitive protective strategies. Future research is needed in order to confirm these findings in a larger sample of both clinical and non-clinical participants and under different conditions for a better understanding of the process that underlies this relationship.

\section{References}

Adler, C. M., Holland, S. K., Schmithorst, V., Tuchfarber, M. J. \& Strakowski, S. M. (2004). Changes in neuronal activation in patients with bipolar disorder during performance of a working memory task. Bipolar Disorders, 6(6), 540-549. http://dx. doi.org/10.1111/j.1399-5618.2004.00117.x.

Allen, R. J., Schaefer, A., \& Falcon, T. (2014). Recollecting positive and negative autobiographical memories disrupts working memory. Acta Psychologica, 151, 237-243. http://dx.doi.org/10.1016/j.actpsy.2014.07.003.

American Psychiatric Association (2013). Diagnostic and statistical manual of mental disorders $\left(D S M-5^{\oplus}\right)$. Washington: American Psychiatric Association.

Baddeley, A. (2012). Working memory: Theories, models, and controversies. Annual Review of Psychology, 63, 1-29. http://dx.doi.org/10.1146/annurev-psych-120710100422.

Brooks, S. J. (2016). A debate on working memory and cognitive control: Can we learn about the treatment of substance use disorders from the neural correlates of anorexia nervosa? BMC Psychiatry, 16(1), 10. http://dx.doi.org/10.1186/s12888-016-0714-z.

Brooks, S. J., Funk, S. G., Young, S. Y., \& Schiöth, H. B. (2017). The role of working memory for cognitive control in anorexia nervosa versus substance use disorder. Frontiers in Psychology, 8, 1651. http://dx.doi.org/10.3389/fpsyg.2017.01651.

Cavalera, C., Pagnini, F., Zurloni, V., Diana, B., Realdon, O., Castelnuovo, G., ... Molinari, E. (2017). Erratum to: Shame proneness and eating disorders: A comparison between clinical and non-clinical samples. Eating and Weight Disorders-Studies on Anorexia, Bulimia and Obesity, 22(2), 379. http://dx.doi.org/10.1007/s40519-017-0376y (1-1).

Cavalera, C., \& Pepe, A. (2014). Social emotions and cognition: Shame, guilt and working memory. Procedia - Social and Behavioral Sciences, 112, 457-464. http://dx.doi.org/ 10.1016/j.sbspro.2014.01.1189.

Cavalera, C., Pepe, A., Diana, D., Zurloni, V., \& Realdon, O. (2017). Factor structure and psychometric properties of the State Shame and Guilt Scale. Testing, Psychometrics, Methodology in Applied Psychology, 24(1), 99-106. http://dx.doi.org/10.4473/ TPM24.1.6.

Christopher, G., \& MacDonald, J. (2005). The impact of clinical depression on working memory. Cognitive Neuropsychiatry, 10(5), 379-399. http://dx.doi.org/10.1080/ 13546800444000128.

Cohen, J. (1992). Statistical power analysis. Current Directions in Psychological Science, 1(3), 98-101. http://dx.doi.org/10.1080/13546800444000128.

Cohen, J. E. (1988). Statistical Power Analysis for the Behavioral Sciences. Hillsdale: Lawrence Erlbaum Associates.

Conway, A. R., Cowan, N., \& Bunting, M. F. (2001). The cocktail party phenomenon revisited: The importance of working memory capacity. Psychonomic Bulletin \& Review, 8(2), 331-335. http://dx.doi.org/10.3758/bf03196169.

Course-Choi, J., Saville, H., \& Derakshan, N. (2017). The effects of adaptive working memory training and mindfulness meditation training on processing efficiency and worry in high worriers. Behaviour Research and Therapy, 89, 1-13. http://dx.doi.org/ 10.1016/j.brat.2016.11.002.

Curci, A., Lanciano, T., Soleti, E., \& Rimé, B. (2013). Negative emotional experiences arouse rumination and affect working memory capacity. Emotion, 13(5), 867-880. http://dx.doi.org/10.1037/a0032492.

Della Sala, S., Foley, J. A., Beschin, N., Allerhand, M., \& Logie, R. H. (2010). Assessing dual-task performance using a paper-and-pencil test: Normative data. Archives of Clinical Neuropsychology, 25, 410-419. http://dx.doi.org/10.1093/arclin/acq039.

Doran, J., \& Lewis, C. A. (2012). Components of shame and eating disturbance among clinical and non-clinical populations. European Eating Disorders Review, 20(4), 265-270. http://dx.doi.org/10.1002/erv.1142.

Ferreira, C., Matos, M., Duarte, C., \& Pinto-Gouveia, J. (2014). Shame memories and eating psychopathology: The buffering effect of self-compassion. European Eating Disorders Review, 22(6), 487-494. http://dx.doi.org/10.1002/erv.2322.

Garner, D. M., \& Garfinkel, P. E. (1985). Handbook of psychotherapy for anorexia nervosa and bulimia. New York: Guilford Press.

Gilbert, P., \& Miles, J. (Eds.). (2014). Body shame: Conceptualisation, research and treat ment. London: Routledge.

Gong, X., Xiao, H., \& Wang, D. (2016). Emotional valence of stimuli modulates false recognition: Using a modified version of the simplified conjoint recognition paradigm. Cognition, 156, 95-105. http://dx.doi.org/10.1016/j.cognition.2016.08.002.

Gruenewald, T. L., Kemeny, M. E., Aziz, N., \& Fahey, J. L. (2004a). Acute threat to the social self: Shame, social self-esteem, and cortisol activity. Psychiatric Medicine, 66(6), 915-924. http://dx.doi.org/10.1097/01.psy.0000143639.61693.ef.

Gruenewald, T. L., Kemeny, M. E., Aziz, N., \& Fahey, J. L. (2004b). Acute threat to the social self: Shame, social self-esteem, and cortisol activity. Psychiatric Medicine, 66(6), 915-924. http://dx.doi.org/10.1097/01.psy.0000143639.61693.ef.

Iordan, A. D., Dolcos, S., \& Dolcos, F. (2013). Neural signatures of the response to emotional distraction: A review of evidence from brain imaging investigations. Frontiers in Human Neuroscience, 7, 200. http://dx.doi.org/10.3389/fnhum.2013. 00200.

Israel, M., Klein, M., Pruessner, J., Thaler, L., Spilka, M., Efanov, S., ... Van den Eynde, F. (2015). N-back task performance and corresponding brain-activation patterns in women with restrictive and bulimic eating-disorder variants: Preliminary findings. Psychiatry Research: Neuroimaging, 232(1), 84-91. http://dx.doi.org/10.1016/j. pscychresns.2015.01.022.

Keith, L., Gillanders, D., \& Simpson, S. (2009). An exploration of the main sources of shame in an eating-disordered population. Clinical Psychology \& Psychotherapy, 16(4), 317-327. http://dx.doi.org/10.1002/cpp.629.

Kim, S., Thibodeau, R., \& Jorgensen, R. S. (2011). Shame, guilt, and depressive symptoms: A meta-analytic review. Psychological Bulletin, 137(1), 68-69. http://dx.doi.org/10. 
$1037 / \mathrm{a} 0021466$.

Klein, K., \& Boals, A. (2001). The relationship of life event stress and working memory capacity. Applied Cognitive Psychology, 15(5), 565-579. http://dx.doi.org/10.1002/ acp.727.

Levinson, C. A., Byrne, M., \& Rodebaugh, T. L. (2016). Shame and guilt as shared vulnerability factors: Shame, but not guilt, prospectively predicts both social anxiety and bulimic symptoms. Eating Behaviors, 22, 188-193. http://dx.doi.org/10.1016/j. eatbeh.2016.06.016.

Lewis, H. B. (1971). Shame and guilt in neurosis. New York, NY: International Universities Press.

Magee, J. C., \& Zinbarg, R. E. (2007). Suppressing and focusing on a negative memory in social anxiety: Effects on unwanted thoughts and mood. Behaviour Research and Therapy, 45(12), 2836-2849. http://dx.doi.org/10.1016/j.brat.2007.05.003.

Manzoni, G. M., Pagnini, F., Gorini, A., Preziosa, A., Castelnuovo, G., Molinari, E., \& Riva, G. (2009). Can relaxation training reduce emotional eating in women with obesity? An exploratory study with 3 months of follow-up. Journal of the American Dietetic Association, 109(8), 1427-1432. http://dx.doi.org/10.1016/j.jada.2009.05.004.

Matos, M., Ferreira, C., Duarte, C., \& Pinto-Gouveia, J. (2015). Eating disorders: When social rank perceptions are shaped by early shame experiences. Psychology and Psychotherapy: Theory, Research and Practice, 88(1), 38-53. http://dx.doi.org/10. $1111 /$ papt.12027.

Mitchell, R. L., \& Phillips, L. H. (2007). The psychological, neurochemical and functional neuroanatomical mediators of the effects of positive and negative mood on executive functions. Neuropsychologia, 45(4), 617-629. http://dx.doi.org/10.1016/j. neuropsychologia.2006.06.030.

Miyake, A., \& Shah, P. (1999). Models of working memory: Mechanisms of active maintenance and executive control. New York, NY: Cambridge University Press.

Oei, N. Y., Everaerd, W. T., Elzinga, B. M., van Well, S., \& Bermond, B. (2006). Psychosocial stress impairs working memory at high loads: An association with cortisol levels and memory retrieval. Stress, 9(3), 133-141. http://dx.doi.org/10. 1080/10253890600965773.

Orth, U., Robins, R. W., \& Soto, C. J. (2010). Tracking the trajectory of shame, guilt, and pride across the life span. Journal of Personality and Social Psychology, 99(6), 1061. http://dx.doi.org/10.1037/a0021342.

Pedhazur, E. J. (1997). Multiple regression in behavioural research (2nd ed.). Fort Worth: Harcourt Brace.

Pessoa, L. (2008). On the relationship between emotion and cognition. Nature Reviews.
Neurology, 9(2), 148-158. http://dx.doi.org/10.1038/nrn2317.

Robinaugh, D. J., \& McNally, R. J. (2010). Autobiographical memory for shame or guilt provoking events: Association with psychological symptoms. Behaviour Research and Therapy, 48(7), 646-652. http://dx.doi.org/10.1016/j.brat.2010.03.017.

Schweizer, S., \& Dalgleish, T. (2016). The impact of affective contexts on working memory capacity in healthy populations and in individuals with PTSD. Emotion, 16(1), 16-23. http://dx.doi.org/10.1037/emo0000072.

Söderqvist, S., Nutley, S. B., Peyrard-Janvid, M., Matsson, H., Humphreys, K., Kere, J., \& Klingberg, T. (2012). Dopamine, working memory, and training induced plasticity: Implications for developmental research. Developmental Psychology, 48(3), 836. http://dx.doi.org/10.1037/a0026179.

Storbeck, J., Davidson, N. A., Dahl, C. F., Blass, S., \& Yung, E. (2015). Emotion, working memory task demands and individual differences predict behavior, cognitive effort and negative affect. Cognition and Emotion, 29(1), 95-117. http://dx.doi.org/10. 1080/02699931.2014.904222.

Stout, D. M., \& Rokke, P. D. (2010). Components of working memory predict symptoms of distress. Cognition and Emotion, 24(8), 1293-1303. http://dx.doi.org/10.1080/ 02699930903309334.

Tangney, J. P., \& Dearing, R. L. (2002). Emotions and social behavior. Shame and guilt. New York: Guilford Press.

Tangney, J. P., Stuewig, J., \& Mashek, D. J. (2007). Moral emotions and moral behavior. Annual Review of Psychology, 58, 345-372. http://dx.doi.org/10.1146/annurev. psych.56.091103.070145.

Tracy, J. L., Robins, R. W., \& Tangney, J. P. (Eds.). (2007). The self-conscious emotions: Theory and research. New York, NY: Guilford Press.

Williams, J. M. G., Barnhofer, T., Crane, C., Herman, D., Raes, F., Watkins, E., \& Dalgleish, T. (2007). Autobiographical memory specificity and emotional disorder. Psychological Bulletin, 133(1), 122-148. http://dx.doi.org/10.1037/0033-2909.133.1.122.

Wiswede, D., Münte, T. F., Goschke, T., \& Rüsseler, J. (2009). Modulation of the errorrelated negativity by induction of short-term negative affect. Neuropsychologia, 47(1), 83-90. http://dx.doi.org/10.1016/j.neuropsychologia.2008.08.016.

Wong, M., \& Qian, M. (2016). The role of shame in emotional eating. Eating Behaviors, 23, 41-47. http://dx.doi.org/10.1016/j.eatbeh.2016.07.004.

Yiend, J. (2010). The effects of emotion on attention: A review of attentional processing of emotional information. Cognition and Emotion, 24(1), 3-47. http://dx.doi.org/10. 1080/02699930903205698. 